\title{
Effects of Mixed-Action $\kappa / \mu$ Opioids on Cocaine Self-Administration and Cocaine Discrimination by Rhesus Monkeys
}

\author{
Carrie A Bowen ',3, S Stevens Negus', Rushi Zong', John L Neumeyer', Jean M Bidlack ${ }^{2}$ and Nancy K Mello*,' \\ 'Alcohol and Drug Abuse Research Center, McLean Hospital-Harvard Medical School, Belmont, MA, USA; ${ }^{2}$ Department of Pharmacology and \\ Physiology, University of Rochester, Rochester, NY, USA
}

\begin{abstract}
$\kappa$-Opioid agonists may functionally antagonize some behavioral effects of cocaine, but the role of mixed $\kappa / \mu$ receptor activity is unclear. The effects of three mixed $\kappa / \mu$ agonists (MCL-IOI, (-)cyclorphan, and Mr2034) and one $\kappa$-selective agonist (enadoline) on cocaine selfadministration and cocaine discrimination were compared in rhesus monkeys. Acute treatment with all $\kappa$ agonists dose dependently reduced cocaine-maintained responding and produced a downward shift in the cocaine self-administration dose-effect curve $(0.00 \mathrm{I}-$ $0.32 \mathrm{mg} / \mathrm{kg} / \mathrm{inj}$, i.v.). During 7 days of chronic treatment, (-)cyclorphan $(0.0032-0.032 \mathrm{mg} / \mathrm{kg} / \mathrm{h})$ and $\mathrm{MCL}-101$ (0.0032-0.032 mg/ kg/h) each dose dependently reduced cocaine self-administration maintained by a dose near the peak of the cocaine self-administration doseeffect curve. MCL-IOI $(0.032 \mathrm{mg} / \mathrm{kg} / \mathrm{h})$ produced selective and sustained decreases in cocaine self-administration, whereas $(-)$ cyclorphan $(0.032 \mathrm{mg} / \mathrm{kg} / \mathrm{h})$ had selective but transient effects. In addition, these mixed $\kappa / \mu$ agonists produced fewer side effects (some salivation) than the $\kappa$-selective agonist (sedation, salivation, emesis). However, none of these $\kappa$ agonists substituted for or antagonized cocaine's discriminative stimulus effects in monkeys trained to discriminate cocaine $(0.4 \mathrm{mg} / \mathrm{kg}$, i.m. $)$ from saline. Thus, $\kappa$ and mixed $\kappa / \mu$-opioid agonists may reduce cocaine self-administration without altering cocaine's discriminative stimulus effects. Mixed $\kappa / \mu$ agonists appear to offer some advantages over selective $\kappa$ agonists as potential treatments for cocaine abuse.

Neuropsychopharmacology (2003) 28, I I25-II39, advance online publication, 5 March 2003; doi: I 0.1038/sj.npp. I 300 I 05
\end{abstract}

Keywords: cocaine abuse; $\kappa$ opioids; cocaine self-administration; cocaine discrimination

\section{INTRODUCTION}

Cocaine abuse continues to be a major public health problem (NIDA, 2000), and no consistently effective pharmacotherapy has been developed (Mendelson and Mello, 1996). The abuse-related effects of cocaine are mediated, in part, by increases in extracellular dopamine levels in the mesolimbic dopamine system (Johanson and Fischman, 1989; Koob and Bloom, 1988; Kuhar et al, 1991; Ritz et al, 1987). Accordingly, one treatment strategy has involved modulation of cocaine's dopaminergic effects. For example, dopamine receptor antagonists, which block the indirect dopamine agonist effects of cocaine, have been

\footnotetext{
*Correspondence: Dr NK Mello, Alcohol and Drug Abuse Research Center, McLean Hospital, Harvard Medical School, II 5 Mill Street, Belmont, MA 02478, USA, Tel: +I 617855 2478, Fax: +| 617855 25।9, E-mail: mello@mclean.harvard.edu

${ }^{3}$ Current address: Scion Pharmaceuticals, Inc., 200 Boston Avenue, Suite 3600, Medford, MA 02155, USA

Received 17 July 2002; revised 8 October 2002; accepted 15 October 2002

Online publication: 3 I October 2002 at http://www.acnp.org/citations/ Npp 103102420
}

studied in animal models of cocaine self-administration (see Mello and Negus, 1996, for a review). However, these drugs produce only a transient blockade of the abuse-related effects of cocaine and potentially severe side effects complicate their use as pharmacotherapies (Kleven and Woolverton, 1990; Negus et al, 1996).

An alternative approach to modulation of cocaine's dopaminergic effects is to administer $\kappa$-opioid receptor agonists (Archer et al, 1996). $\kappa$ Agonists attenuate a number of neurobiological effects of cocaine in rats, such as cocaineinduced increases in extracellular dopamine levels in the nucleus accumbens (Maisonneuve et al, 1994) and immediate-early gene expression in the striatum (Crawford et al, 1995; Steiner and Gerfen, 1995). In behavioral studies in rodents, $\kappa$ agonists attenuated cocaine-induced place preferences (Crawford et al, 1995; Mori et al, 2002; Suzuki et al, 1992), reinstatement of extinguished cocaine-taking behavior (Schenk et al, 2000), locomotor activity and stereotypies (Crawford et al, 1995; Heidbreder et al, 1993; Vanderschuren et al, 2000), and sensitization to cocaineinduced locomotor activity and stereotypies (Heidbreder $e t$ al, 1993; Shippenberg and Rea, 1997) (see for a review Mello and Negus, 2000; Shippenberg et al, 2001). 
There is increasing evidence that $\kappa$ agonists also reduce cocaine self-administration in rodents (Archer et al, 1996; Glick et al, 1995; Schenk et al, 1999) and nonhuman primates (Mello and Negus, 1998; Negus et al, 1997). In rhesus monkeys, the effects of chronic treatment with four arylacetamide and four benzomorphan $\kappa$ agonists on cocaine- and food-maintained responding were evaluated (Mello and Negus, 1998; Negus et al, 1997). The results suggested that at least two pharmacological characteristics may be important determinants of $\kappa$-opioid effects. First, the magnitude of effect on cocaine self-administration was related directly to efficacy at $\kappa$ receptors (see for a review Mello and Negus, 2000). For example, the high-efficacy $\kappa$ agonists enadoline and Mr2033 dose dependently decreased cocaine self-administration, whereas the low-efficacy $\kappa$ agonist cyclazocine and the $\kappa$ antagonist nor-binaltorphimine did not. Second, the selectivity of the ligand for $\kappa-v s$ $\mu$-opioid receptors also influenced $\kappa$-opioid effects on cocaine self-administration. For example, three of the five $\kappa$ agonists that were most effective in decreasing cocaine self-administration (ethylketocyclazocine (EKC), Mr2033, bremazocine) have $\mu$ receptor activity in some pharmacological and in vitro binding studies (Butelman et al, 1993; Davis et al, 1992; Emmerson et al, 1994; France et al, 1994; Gmerek et al, 1987). These findings were consistent with the hypothesis first advanced by Archer et al (1996) that $\kappa / \mu$ opioid combinations might be useful for the treatment of cocaine abuse. Since both $\kappa$ agonists and $\mu$ antagonists reduce dopamine release from the nucleus accumbens, it was suggested that this combination might be effective for cocaine-abuse treatment (Archer et al, 1996). Finally, the occurrence of undesirable side effects was inversely related to the selectivity of the ligand for $\kappa v s \mu$-opioid receptors. Specifically, highly selective $\kappa$ agonists, such as enadoline, decreased cocaine self-administration but only at doses that also produced severe undesirable side effects, whereas $\kappa$ agonists with $\mu$ receptor activity reduced cocaine selfadministration with fewer and less severe side effects. These findings suggested that high-efficacy $\kappa$ agonists with $\mu$ receptor activity may be especially promising as candidate treatments for cocaine dependence.

To further evaluate this hypothesis, we examined the effects of acute treatment with four $\kappa$ agonists that differed in relative selectivity for $\mu$ and $\kappa$ receptors. A novel series of morphinans was synthesized, and their binding affinities and selectivities for $\kappa-, \mu$-, and $\delta$-opioid receptors were characterized (Neumeyer et al, 2000a, b, 2001). Two compounds were selected for behavioral evaluation in the present study to examine the degree to which $\kappa$ agonist effects on cocaine self-administration and cocaine discrimination are influenced by (1) relative selectivity for $\kappa v s \mu$ receptors and (2) relative efficacy at $\mu$ receptors. The morphinans $(-)$ cyclorphan and its $N$-cyclobutyl analog, MCL-101, bind with similar affinities to $\kappa$ and $\mu$ receptors. However, MCL-101 has a higher efficacy at $\mu$ receptors and functions as a $\kappa$ agonist/ $\mu$ agonist, whereas $(-)$ cyclorphan has low efficacy at $\mu$ receptors and functions as a $\kappa$ agonist/ $\mu$ antagonist (Neumeyer et al, 2000a,b, 2001). These morphinans were compared with a benzomorphan, Mr2034 (the active enatiomer of Mr2033), that has high efficacy at $\kappa$ receptors, binds to $\kappa$ and $\mu$ receptors with similar affinities and produces both $\kappa$ and $\mu$ agonist effects
(Hutchinson et al, 1975; Magnan et al, 1982; Wood et al, 1981; Bidlack, unpublished data). Finally, the acute effects of the arylacetamide, enadoline, were examined. Like Mr2034, enadoline has high efficacy at $\kappa$ receptors, but it differs in that it also is highly selective for $\kappa$ receptors (Hunter et al, 1990). Both Mr2033 and enadoline dose dependently decreased cocaine self-administration during chronic treatment (Mello and Negus, 1998).

The acute effects of all four $\kappa$-opioid agonists on complete cocaine self-administration dose-effect functions were examined using a Rapid Assessment Procedure (Caine et al, 2000). The chronic effects of $(-)$ cyclorphan and MCL101 on cocaine self-administration were studied for 7 days using the same procedure previously used to evaluate enadoline and Mr2033 (Mello and Negus, 1998). Foodmaintained responding was measured in both acute and chronic treatment procedures to evaluate the selectivity of $\kappa$ agonist effects on cocaine-maintained responding.

Since the drug discrimination procedures can be useful for clarifying the mechanisms of action of drugs that affect cocaine self-administration, we compared the acute effects of four $\kappa$ agonists in both procedures. The same drug discrimination procedures were used in the present study and in our previous study of the effects of the $\kappa$-opioid agonists U50 488 and EKC on cocaine discrimination in rhesus monkeys (Negus and Mello, 1999). $\kappa$-opioid agonist effects on cocaine discrimination have been inconsistent and a number of procedural and species differences may have contributed to these results. In squirrel monkeys, the $\kappa$ agonists U50488 and enadoline attenuated cocaine's discriminative stimulus effects (Spealman and Bergman, 1992, 1994). However, the $\kappa$ agonists U50 488 and EKC did not consistently alter cocaine discrimination performance in rhesus monkeys (Negus and Mello, 1999). In rats, both attenuation of cocaine discrimination (Kantak et al, 1999; Mori et al, 2002) and no effect have been reported (Broadbent et al, 1995; Suzuki et al, 1997; Woolfolk and Holtzman, 1997).

\section{METHODS}

\section{Subjects}

Three experiments were conducted in 14 adult male rhesus monkeys (Macaca mulatta). Cocaine self-administration studies were conducted in eight monkeys. Four animals were trained to self-administer cocaine using a Rapid Assessment Procedure (Caine et al, 2000) and the acute effects of $\kappa$ agonist treatments on cocaine- and foodmaintained responding were evaluated. Four additional animals were trained to self-administer cocaine under a second-order schedule using the same procedure previously used to evaluate chronic $\kappa$ agonist effects on cocaine selfadministration (Mello and Negus, 1998; Negus et al, 1997). Drug discrimination studies were conducted in a separate group of six monkeys. Two of the monkeys trained to selfadminister cocaine using the Rapid Assessment Procedure were experimentally naive at the beginning of these experiments. All of the other monkeys had an experimental history involving the evaluation of dopaminergic and/or opioid compounds in assays of cocaine self-administration or cocaine discrimination. Monkeys weighed $7.0-12.0 \mathrm{~kg}$ 
and were maintained on a diet of multiple vitamins, fresh fruit, and Lab Diet Jumbo Monkey biscuits (PMI Feeds, Inc., St Louis, MO). In addition, monkeys could receive 1-g banana-flavored pellets (Precision Primate Pellets Formula L/I Banana Flavor, PJ Noyes Co., Lancaster, NH) during daily operant sessions (see below). Water was available continuously. A 12-h light-dark cycle was in effect (lights on from 7 am to $7 \mathrm{pm}$ ).

Animal maintenance and research were conducted according to the guidelines provided by the National Institutes of Health Committee on Laboratory Animal Resources. The research facility was licensed by the United States Department of Agriculture. Research protocols were approved by the McLean Hospital Institutional Animal Care and Use Committe. A consulting veterinarian monitored the health of the monkeys on a regular basis. Monkeys had visual, auditory, and olfactory contact with other monkeys throughout the study. To provide environmental enrichment, each animal was supplied with toys, and music or a nature videotape was played daily. In addition, the operant procedures provided opportunities for environmental manipulation (Line et al, 1989).

\section{Cocaine Self-Administration}

Surgery and catheter maintenance. For intravenous drug administration, a chronic double-lumen catheter was implanted into a jugular or femoral vein under aseptic conditions. The double-lumen catheter permitted simultaneous i.v. cocaine self-administration and i.v. test drug administration. Monkeys were sedated with ketamine (5$10 \mathrm{mg} / \mathrm{kg}$, i.m.) and anesthesia was induced with a ketamine $(50 \mathrm{mg} / \mathrm{ml}) /$ diazepam $(2.5 \mathrm{mg} / \mathrm{ml})$ mixture $(0.1-0.15 \mathrm{ml} / \mathrm{kg}$, i.v.) to allow for tracheal intubation. Atropine $(0.05 \mathrm{mg} / \mathrm{kg}$, i.m.) was administered to reduce salivation and buprenorphine $(0.05 \mathrm{mg} / \mathrm{kg}$, i.m.) was given for intraoperative analgesia. General anesthesia was maintained with isoflurane ( $2 \%$ mixed with oxygen). A 20 gauge i.v. catheter was inserted into a saphenous vein for intraoperative fluid administration $(0.9 \% \mathrm{NaCl}, 10 \mathrm{ml} / \mathrm{kg} / \mathrm{h})$. Following a skin incision, blunt dissection was performed to expose the vessel. A small incision was made in the vein using Vannas scissors. A silicone rubber double-lumen catheter (inside diameter $0.71 \mathrm{~mm}$, outside diameter $2.2 \mathrm{~mm}$ ) was inserted into the vein using a catheter introducer and secured in place with sutures. The catheter was passed subcutaneously to an exit site at the mid-scapular region. The muscle overlaying the vein was closed with sutures, and the skin incision was closed with Nexaband ${ }^{\circledR}$ adhesive. Buprenorphine $(0.05 \mathrm{mg} / \mathrm{kg}$, i.m. $)$ and Penicillin G procaine $(20000 \mathrm{IU} / \mathrm{kg}$, i.m.) were administered at the end of the surgical procedure. Following surgery, buprenorphine $(0.1 \mathrm{mg} / \mathrm{kg}$, i.m.) and cefazolin $(30 \mathrm{mg} / \mathrm{kg}$, i.m.) were administered twice daily for 5 days.

Each monkey was fitted with a nylon vest (Lomir Biomedical, Montreal, Canada) attached to a flexible stainless-steel cable. The other end of the cable was attached to a fluid swivel. This tether system protected the i.v. catheter and allowed freedom of movement for the animal. Catheter patency was monitored periodically by i.v. administration of ketamine $(5 \mathrm{mg} / \mathrm{kg})$ or a short-acting barbiturate, methohexital $(4 \mathrm{mg} / \mathrm{kg})$. The catheter was considered patent if i.v. ketamine or methohexital administration resulted in loss of muscle tone within $10 \mathrm{~s}$.

\section{Behavioral Apparatus}

Drug self-administration. Drug self-administration sessions occurred in each monkey's home cage $(65.7 \times$ $\left.99.9 \times 5.9 \mathrm{~cm}^{3}\right)$. The front wall of each cage was adapted for the attachment of an operant panel $\left(28 \times 28 \mathrm{~cm}^{2}\right)$. The operant panel included three square translucent response keys $\left(6.4 \times 6.4 \mathrm{~cm}^{2}\right)$ arranged $2.5 \mathrm{~cm}$ apart horizontally and $3.2 \mathrm{~cm}$ from the top of the panel. Each response key could be transilluminated by red, green, or yellow stimulus lights (Superbright LEDs). A food-pellet dispenser (Gerbrands, model G5210) was mounted above each cage to deliver $1 \mathrm{~g}$ banana-flavored food pellets to a receptacle $(6.0 \times$ $5.0 \times 3.0 \mathrm{~cm}^{3}$ ) located below the operant panel. Up to three infusion pumps (Model B5P-1E, Braintree Scientific, Braintree, MA; or Model 980210, Harvard Apparatus, South Natick, MA) were mounted above each cage to deliver solutions from $60-\mathrm{ml}$ plastic syringes via the i.v. catheter. One infusion pump delivered response-contingent cocaine injections through one lumen of the double-lumen catheter. The other infusion pumps delivered noncontingent saline or test drug solution through the other lumen of the catheter. The schedules of reinforcement were controlled and data were collected with an IBM-compatible computer and Med Associates, Inc. (Georgia, VT) interface and power supply located in a separate room. Room lights were extinguished during all food and drug self-administration sessions.

Drug discrimination. Each monkey was housed in a ventilated, stainless-steel cage $\left(56 \times 71 \times 69 \mathrm{~cm}^{3}\right)$. The front wall of each cage was adapted to fit an operant panel $\left(28 \times 28 \mathrm{~cm}^{2}\right)$. A food-pellet dispenser (Gerbrands, model G5210) was mounted on top of the panel and delivered 1-g banana-flavored food pellets to a receptacle beneath the operant panel. The schedules of reinforcement were controlled and data were collected with an IBM-compatible computer and Med Associates Inc. (Georgia, VT) interface and power supply.

\section{Behavioral Observations}

High-efficacy $\kappa$-opioid agonists sometimes produce undesirable side effects during the first 2 or 3 days of treatment (Negus et al, 1997; Mello and Negus, 1998). Accordingly, animals were observed after each acute $\kappa$ agonist treatment session to determine if vomiting, salivation, or profound sedation occurred. Sedation was evaluated by general observation and by determining if animals would take a food treat. The same procedures were used in studies of chronic $\kappa$ agonist treatment, but observations were made only after the two daytime sessions as described below. All staff were trained to conduct these behavioral observations.

\section{Behavioral Procedures}

Three separate experiments were conducted in different groups of animals to examine the acute and chronic effects of $\kappa$ agonists on the abuse-related effects of cocaine. In 
Study 1 , the acute effects of $\kappa$-opioid agonists on cocaine self-administration dose-effect curves and food-maintained responding were studied. In Study 2, the chronic effects of $\kappa$-opioid agonists on responding maintained by food and by a dose of cocaine $(0.01 \mathrm{mg} / \mathrm{kg} / \mathrm{inj})$ near the peak of the dose-effect curve were studied. In Study 3, the acute effects of $\kappa$-opioid agonists on cocaine discrimination were evaluated. The behavioral procedures and data analysis procedures for each study are described below.

\section{Study 1: Acute Effects of $\kappa$ Agonists on Responding Maintained by Cocaine and Food}

Rapid assessment procedure. The acute effects of $\kappa$ agonists on responding maintained by cocaine and food under a fixed-ratio (FR) 30 schedule of reinforcement were examined. A Rapid Assessment Procedure was used to study selfadministration of multiple unit doses of cocaine within a single experimental session (Caine et al, 2000). Each 2-h session consisted of six components separated by $10-\mathrm{min}$ intercomponent time-out (TO) periods. During the first and sixth components, food pellets were available for $5 \mathrm{~min}$, and the center response key was transilluminated with a red stimulus light. During the second, third, fourth, and fifth components, i.v. injections of saline or cocaine were available for $15 \mathrm{~min}$. Each drug component was initiated by the 10-s transillumination of the center response key with a yellow stimulus light and the noncontingent delivery of a single 'priming' injection of saline or the unit dose of cocaine that was available for self-administration. When cocaine or saline was available, the center response key was transilluminated with a green stimulus light. A 10-s TO followed the completion of the ratio requirement for each food pellet or injection and was signaled by the transillumination of the center response key with a yellow stimulus light. During the 10-min intercomponent TO periods, all stimulus lights were turned off, and responses had no scheduled consequences. Experimental sessions began at $3 \mathrm{pm}$ and were conducted 7 days/week.

Varying the unit dose of cocaine within operant sessions. The unit dose of cocaine available during each component of the self-administration session was determined by (1) the duration of each infusion, which determined the volume and (2) the concentration of drug in the syringe. During most sessions, the syringe pumps were programmed to deliver the following volumes during the four consecutive drug components: $32 \mu \mathrm{l}$ in $0.32 \mathrm{~s}, 100 \mu \mathrm{l}$ in $1 \mathrm{~s}, 320 \mu \mathrm{l}$ in $3.2 \mathrm{~s}$, and $1000 \mu \mathrm{l}$ in $10 \mathrm{~s}$. A different cocaine dose range could be studied by changing the cocaine concentration in the syringe. Complete cocaine dose-effect functions were determined across sessions by studying overlapping cocaine dose ranges. An ascending dose series was used to reduce the possibility that the dose of cocaine available in one component would influence cocaine-maintained behavior in subsequent drug components.

Rapid assessment procedure training. Initially, food was available for all six components of the session, and monkeys were trained to respond for food pellets under the FR 30, TO 10 -s schedule. After food reliably maintained responding, monkeys were trained to self-administer cocaine $(0.032 \mathrm{mg} /$ $\mathrm{kg} / \mathrm{inj}$ ). Then availability of the cocaine training dose and saline was alternated until reliable extinction was observed. Training was considered complete when the following criteria were met: (1) the peaks of the overlapping cocaine dose-effect curves were within one half-log unit of each other, (2) the overall mean cocaine dose-effect function was characterized by an inverted ' $U$ ' shape, (3) saline-maintained responding was reliably lower than peak cocainemaintained responding and (4) food-maintained responding was stable (criterion of $\leqslant 20 \%$ deviation from the mean of five consecutive sessions).

Rapid assessment procedure testing. To ensure that the effects of the $\kappa$-opioid agonists were sustained during the entire 2-h test session, all test compounds were delivered by continuous intravenous infusion through the second lumen of the double-lumen catheter. Each $\kappa$ opioid was delivered at a rate of $3.3 \mathrm{ml} / \mathrm{h}$ by infusing a volume of $100 \mu \mathrm{l}$ approximately every $2 \mathrm{~min}$ for a total of $3 \mathrm{~h}$. Test drug administration began $1 \mathrm{~h}$ before the test session to fill the 'dead space' in the catheter (approximately $1 \mathrm{ml}$ ).

Four $\kappa$-opioid agonists were evaluated. Enadoline (0.00032-0.01 mg/kg/h), (-)cyclorphan $\quad(0.001-0.032 \mathrm{mg} / \mathrm{kg} /$ h), Mr2034 (0.001-0.01 mg/kg/h), and MCL-101 (0.001$0.032 \mathrm{mg} / \mathrm{kg} / \mathrm{h}$ ). Usually, test sessions were interspersed between training sessions that evaluated responding maintained by (1) the cocaine training dose only, (2) saline only, and (3) a range of cocaine doses. A test was conducted only if the peak of the most recently determined cocaine selfadministration dose-effect function was within one half-log unit of that previously observed. Each dose of a test compound was investigated at least once in each animal. When possible, doses were tested two to three times with overlapping dose ranges of cocaine. Tests were conducted no more than twice/ week with a minimum of $48 \mathrm{~h}$ between test sessions.

Data analysis. The primary dependent variables were the number of food pellets and drug injections delivered during each component of a 2 -h test session. Mean food and cocaine data are presented for three doses of each $\kappa$ agonist. Data from individual monkeys are presented to illustrate the effects of the highest dose of each $\kappa$ agonist on food- and cocaine-maintained responding. Data were analyzed using repeated measures analysis of variance (ANOVA; SuperAnova, Abacus Concepts, Inc., Berkeley, CA) with $\kappa$ agonist dose and cocaine dose or food component as the two withinsubjects factors. Owing to the fact that multiple sessions of overlapping cocaine dose ranges were required to characterize a complete cocaine dose-effect function, a mean cocaine dose-effect function was determined for each animal under each condition and subjected to statistical analysis. The criterion for significance was set $a$ priori at $p<0.05$. If the effect of $\kappa$ agonist dose was significant, linear contrasts comparing individual means were carried out to determine which treatment dose was significantly different from saline.

\section{Study 2: Chronic Effects of $\boldsymbol{\kappa}$ Agonists on Responding Maintained by Cocaine or Food}

Cocaine self-administration training procedures. Monkeys were trained to respond for food and cocaine $(0.01 \mathrm{mg} / \mathrm{kg} /$ 
inj) under a second-order schedule (FR 2 [VR16:S]) during multiple daily sessions of food and cocaine availability. Procedures for the evaluation of chronic drug treatment effects on cocaine- and food-maintained responding were identical to those used in our previous studies of the effects of $\kappa$-opioid drugs on cocaine self-administration (Mello and Negus, 1998; Negus et al, 1997). Once monkeys received at least 50 food pellets/day for at least 3 consecutive days under the terminal second-order schedule, the intravenous double-lumen catheter was implanted as described above. After recovery from surgery for at least 1 week, key-pressing for $0.032 \mathrm{mg} / \mathrm{kg} / \mathrm{inj}$, i.v., cocaine was shaped under a series of increasing variable ratios identical to those used during training of food-maintained responding. The final secondorder schedule response requirement was identical for food- and drug-maintained responding (FR 2 [VR 16:S]). There were four food and cocaine sessions in each experimental day. Food sessions began at $11 \mathrm{am}, 3 \mathrm{pm}$, $7 \mathrm{pm}$, and $6 \mathrm{am}$. Cocaine sessions began at 12 noon, $4 \mathrm{pm}$, $8 \mathrm{pm}$, and $7 \mathrm{am}$. Each food or drug session lasted $1 \mathrm{~h}$ or until a maximum of 25 food pellets or 20 injections had been delivered, whichever occurred first. Thus, monkeys could earn a maximum of 80 cocaine injections/day and $100 \mathrm{food}$ pellets/day.

As in the Rapid Assessment Procedure, the conditions of food and cocaine availability were associated with different colored stimulus lights. The center key was transilluminated with a red stimulus light during food sessions and a green stimulus light during cocaine sessions. At the onset of reinforcer delivery, and after completion of each VR component of the second-order schedule, the appropriate colored stimulus light (red for food, green for injections) was illuminated for $1 \mathrm{~s}$ below the center response key. Each reinforcer delivery was followed by a $10 \mathrm{~s}$ TO.

Monkeys were trained until they met the following criteria for stable food and cocaine self-administration under the terminal schedule: (1) 3 consecutive days during which the number of drug injections/day differed by no more than $20 \%$ from the mean number of drug injections/day during those 3 days, and there was no upward or downward trend, and (2) during the same 3 consecutive days, the mean number of both drug injections/day and food pellets/day was greater than 50 .

Drug self-administration testing. During testing, a unit dose of $0.01 \mathrm{mg} / \mathrm{kg} / \mathrm{inj}$ cocaine was used because it was the lowest dose to maintain reliably high rates of cocaine selfadministration in all monkeys and because previous studies have shown that behavior maintained by this unit dose of cocaine is especially sensitive to the effects of $\kappa$ opioids (Mello and Negus, 1998; Negus et al, 1997). The effects of repeated treatments with saline and each dose of $(-)$ cyclorphan $(0.0032-0.032 \mathrm{mg} / \mathrm{kg} / \mathrm{h})$ and MCL-101 (0.0032$0.032 \mathrm{mg} / \mathrm{kg} / \mathrm{h}$ ) were examined for 7 consecutive days. $\kappa$ agonists were administered continuously by i.v. injections through the second lumen of the double-lumen catheter every $20 \mathrm{~min}$ for a total of three injections/h and 66 injections/day. No injections were delivered between 9 and $11 \mathrm{am}$. During this period, $\kappa$-opioid agonist syringe volumes were recorded and replenished and the health status of the animals was evaluated. At the conclusion of each 7-day test period, the maintenance dose of cocaine $(0.032 \mathrm{mg} / \mathrm{kg} / \mathrm{inj})$ and saline control treatments were reinstated for a period of at least 4 days and until the number of reinforcers/day maintained by cocaine and food returned to baseline levels. During saline control treatment, $0.1 \mathrm{ml}$ of saline was delivered every $20 \mathrm{~min}$ for a total of $6.6 \mathrm{ml} / 22 \mathrm{~h} . \kappa$ agonist doses were tested in an irregular order across monkeys.

Data analysis. The total number of cocaine injections or food pellets delivered/day was determined. Data for the effects of $(-)$ cyclorphan and MCL-101 on self-administration of $0.01 \mathrm{mg} / \mathrm{kg} / \mathrm{inj}$ cocaine were compared with the effects of saline treatment using a two-factor repeated measures ANOVA with $\kappa$ agonist dose and treatment day as the two within-subjects factors. The criterion for significance was set $a$ priori at $p<0.05$. If the effect of $\kappa$ agonist dose was significant, linear contrasts comparing individual means were carried out to determine which treatment dose was significantly different from saline.

\section{Study 3: Cocaine Discrimination Studies}

Discrimination training. The drug discrimination procedures employed in the present study were similar to those used in previous studies of $\kappa$-opioid effects on cocaine discrimination (Negus and Mello, 1999). In the present experiment, the monkeys had been trained previously to discriminate $0.4 \mathrm{mg} / \mathrm{kg}$ cocaine from saline (i.m.). Training sessions consisted of one to five cycles and each cycle consisted of a 15-min TO period followed by a 5-min response period. Monkeys were given an i.m. injection of either vehicle (saline) or the cocaine training dose at the beginning of the 15-min TO period. All stimulus lights were turned off and responding had no scheduled consequences during the TO period. During the response period, the right and left response keys were transilluminated red or green, and key position was counterbalanced across monkeys. Depending upon the training condition, monkeys could respond on the stimulus-appropriate key under an FR 30 schedule to obtain up to 10 food pellets/cycle. After vehicle administration, responding on only the green key resulted in the delivery of a food pellet. After cocaine administration, responding on only the red key resulted in the delivery of food. Inappropriate responses reset the FR requirement on the stimulus-appropriate key. The center key was not illuminated during operant sessions and responding had no scheduled consequences. If all available food pellets were delivered in less than $5 \mathrm{~min}$, then the stimulus lights were extinguished and responding had no scheduled consequences for the remainder of the 5-min response period.

Training sessions consisted of $0-5$ saline cycles followed by $0-1$ drug cycles. If the training drug was administered, it was given only during the last cycle. This design assured a constant interval between drug administration and the onset of response periods during which responding on the drug-appropriate key produced food. Monkeys were considered to have acquired the discrimination when the following criteria were met for seven out of eight consecutive training sessions: (1) the percent injectionappropriate responding before the delivery of the first reinforcer was greater than or equal to $80 \%$ for all cycles, (2) the percent injection-appropriate responding over the entire response period was greater than or equal to $90 \%$ 
for all cycles, and (3) response rates during vehicle training cycles were greater than 0.5 responses/s. Experimental sessions were conducted 5 days/week.

Discrimination testing. Test sessions were conducted only if the three criteria listed above were met during the training day immediately preceding the test day. If responding did not meet criterion levels of discrimination performance, then training was continued until criterion levels of performance were obtained for at least 2 consecutive days. In general, testing was conducted on Tuesdays and Fridays and training sessions were conducted on Mondays, Wednesdays, and Thursdays. Test sessions were identical to training sessions except that responding on either key produced food, and test drugs were adminstered using either a substitution or a pretreatment protocol.

In the substitution protocol, cocaine or a $\kappa$-opioid agonist was administered alone using a cumulative-dosing procedure. The drugs (and doses) tested included cocaine (0.013-1.3 mg/kg), enadoline $(0.0001-0.0032 \mathrm{mg} / \mathrm{kg}),(-)$ cyclorphan (0.001-0.1 mg/kg), Mr2034 (0.0001-0.01 mg/ $\mathrm{kg})$, and MCL-101 (0.001-0.1 mg/kg). Monkeys received an injection of the test compound $5 \mathrm{~min}$ after the onset of the 15-min TO at the beginning of each cycle of a multiple-cycle session. In the cumulative-dosing procedure, each dose increased the total dose by $1 / 4$ or $1 / 2 \log$ units. Dose-effect curves for each compound were determined twice in each monkey using overlapping dose ranges. Each $\kappa$ agonist was tested up to doses that eliminated responding in most of the monkeys.

In the pretreatment protocol, a $\kappa$-opioid agonist dose was administered $15 \mathrm{~min}$ before the determination of a cumulative cocaine dose-effect curve. Since preliminary studies indicated that enadoline had a relatively short duration of action, pretreatment studies with each enadoline dose were determined twice in each monkey with overlapping cocaine dose-effect curves. For one determination, a dose range of $0.013-1.3 \mathrm{mg} / \mathrm{kg}$ cocaine was evaluated in a series of five consecutive cycles, and the total test session lasted $1 \mathrm{~h}$ $40 \mathrm{~min}$. For the second determination, a high dose range of $0.13-1.3 \mathrm{mg} / \mathrm{kg}$ cocaine was tested in a series of three consecutive cycles and the total test session lasted $1 \mathrm{~h}$. This procedure assured that active cocaine doses were evaluated while enadoline was producing its behavioral effects. Pretreatment studies with Mr2034 and MCL-101 also were determined twice in each monkey with overlapping cocaine dose ranges identical to those described above for studies with enadoline. In contrast, preliminary studies indicated that $(-)$ cyclorphan had a relatively long duration of action. Thus, the effects of each dose of $(-)$ cyclorphan were evaluated only once in each monkey before a full dose range of $0.013-1.3 \mathrm{mg} / \mathrm{kg}$ cocaine. The drugs (and doses) tested in pretreatment experiments were enadoline $(0.00032-0.0032 \mathrm{mg} / \mathrm{kg}),(-)$ cyclorphan $(0.0032$ $0.032 \mathrm{mg} / \mathrm{kg}), \mathrm{Mr} 2034(0.0032-0.032 \mathrm{mg} / \mathrm{kg})$, and MCL-101 $(0.0032-0.032 \mathrm{mg} / \mathrm{kg})$. Each $\kappa$ agonist was tested up to pretreatment doses that eliminated responding in most of the monkeys.

Data analysis. Percent cocaine-appropriate responding data are presented in tabular and graphical formats as a function of cumulative drug dose (log scale). The percent cocaine-appropriate responding for a given cycle was calculated and reported only if a monkey emitted enough responses to earn at least one food pellet (i.e. 30 responses, equivalent to a response rate of 0.1 responses/s). In group graphs, data for percent cocaine-appropriate responding are plotted only if at least two monkeys met the response rate criterion.

$\mathrm{ED}_{50}$ values were determined to evaluate the effects of $\kappa$ agonists in substitution and pretreatment tests. An $\mathrm{ED}_{50}$ value was defined as the dose of the test compound that produced $50 \%$ cocaine-appropriate responding. $\mathrm{ED}_{50}$ values were calculated by interpolation when only two data points were available (one below and one above 50\% cocaineappropriate responding) or by linear regression when at least three data points were available on the linear portion of the dose-effect curve. Individual $\mathrm{ED}_{50}$ values were calculated for monkeys that responded during at least the first four response cycles and averaged to yield a mean $\mathrm{ED}_{50}$ value $( \pm$ SEM). Since drug doses were incremented on a logarithmic scale, $\mathrm{ED}_{50}$ values were converted to their log values for the calculation of mean and SEM and for statistical analysis. Mean $\mathrm{ED}_{50}$ values $( \pm \mathrm{SEM})$ were converted back to their linear values for presentation in Table 1.

For pretreatment tests, $\mathrm{ED}_{50}$ values for cocaine administered alone or following pretreatment with $\kappa$ agonists were compared using one-way ANOVA. Statistical analyses included data from tests that resulted in $\mathrm{ED}_{50}$ values for at least three monkeys. For pretreatment doses with one or two missing individual $\mathrm{ED}_{50}$ values, the missing cell(s) were filled with the average $\mathrm{ED}_{50}$ value from the remaining monkeys to permit repeated measures statistical analyses. A significant ANOVA was followed by linear contrasts comparing individual means. In some pretreatment tests, all data points for cocaine-appropriate responding fell below or above $50 \%$. For the purposes of statistical analysis, $\mathrm{ED}_{50}$ values in these cases were estimated by assuming that either (1) the next highest half-log unit dose of cocaine would have produced $100 \%$ cocaine-appropriate responding (in cases where all data points were below 50\%) or (2) the next lowest half-log dose would have produced $0 \%$ cocaine-appropriate responding (in cases were all points were above $50 \%$ ). In addition, response rate data were compared using a two-way ANOVA with cocaine dose and pretreatment drug dose as the two factors. For all statistical analyses, the criterion for significance was set a priori at $p<0.05$.

\section{Drug Solution Preparation}

Cocaine hydrochloride (supplied by the National Institute on Drug Abuse, NIH, Bethesda, MD) was dissolved in sterile saline. Enadoline (supplied by Parke-Davis Pharmaceutical Research, Warner-Lambert Pharmaceuticals, Ann Arbor, MI) was dissolved in sterile water. Mr2034 (provided by Boehringer Ingelheim, Ridgefield, CT) was dissolved in sterile water with $2 \%$ lactic acid and heated slightly. MCL101 ((-)3-hydroxy- $N$-cyclobutylmethyl morphinan $\mathrm{S}(+)$ mandelate), synthesized by JL Neumeyer (Neumeyer et al, 2000a), was dissolved in sterile water with $10 \%$ ethanol, heated slightly and sonicated. (-)Cyclorphan (supplied as 
the $\mathrm{S}(+)$ mandelate salt), synthesized by JL Neumeyer (Neumeyer et al, 2000a), was dissolved in sterile water. All drugs were filter-sterilized using a $0.22 \mu \mathrm{m}$ Millipore filter and stored in pyrogen-free vials. Drugs were prepared as stock solutions and then diluted to the appropriate concentrations with sterile saline. In the drug self-administration experiments, cocaine and $\kappa$ agonists were delivered i.v. in a volume of $0.032-1.0 \mathrm{ml} / \mathrm{inj}$. In the drug discrimination studies, all drugs were administered i.m. in a volume of $0.1-1.0 \mathrm{ml}$.

\section{RESULTS}

\section{Study 1: Cocaine Self-Administration-Acute $\kappa$-opioid} Agonist Treatment

Saline control treatment. The acute effects of $\kappa$-opioid agonists were examined in a Rapid Assessment Procedure that permitted evaluation of responding maintained by food and multiple unit doses of cocaine in two or three experimental sessions (Caine et al, 2000). Figure 1 shows the mean levels of food- and cocaine-maintained responding during saline control treatment (open circles). Responding for food typically resulted in the delivery of 15-20 food pellets during both the first food component (F1), before cocaine availability, and during the second food component (F2), after cocaine availability. Cocaine self-administration dose-effect functions were characterized by an inverted ' $U$ ' shape. The peaks of the group mean cocaine self-administration dose-effect curves occurred at $0.0032 \mathrm{mg} / \mathrm{kg} / \mathrm{inj}$ cocaine throughout the study.

Cocaine- and food-maintained responding by individual monkeys during saline control treatment is shown in Figure 2. Monkeys consistently earned between 15 and 20 pellets during the food components. There was some variability between individuals in the peaks of the cocaine
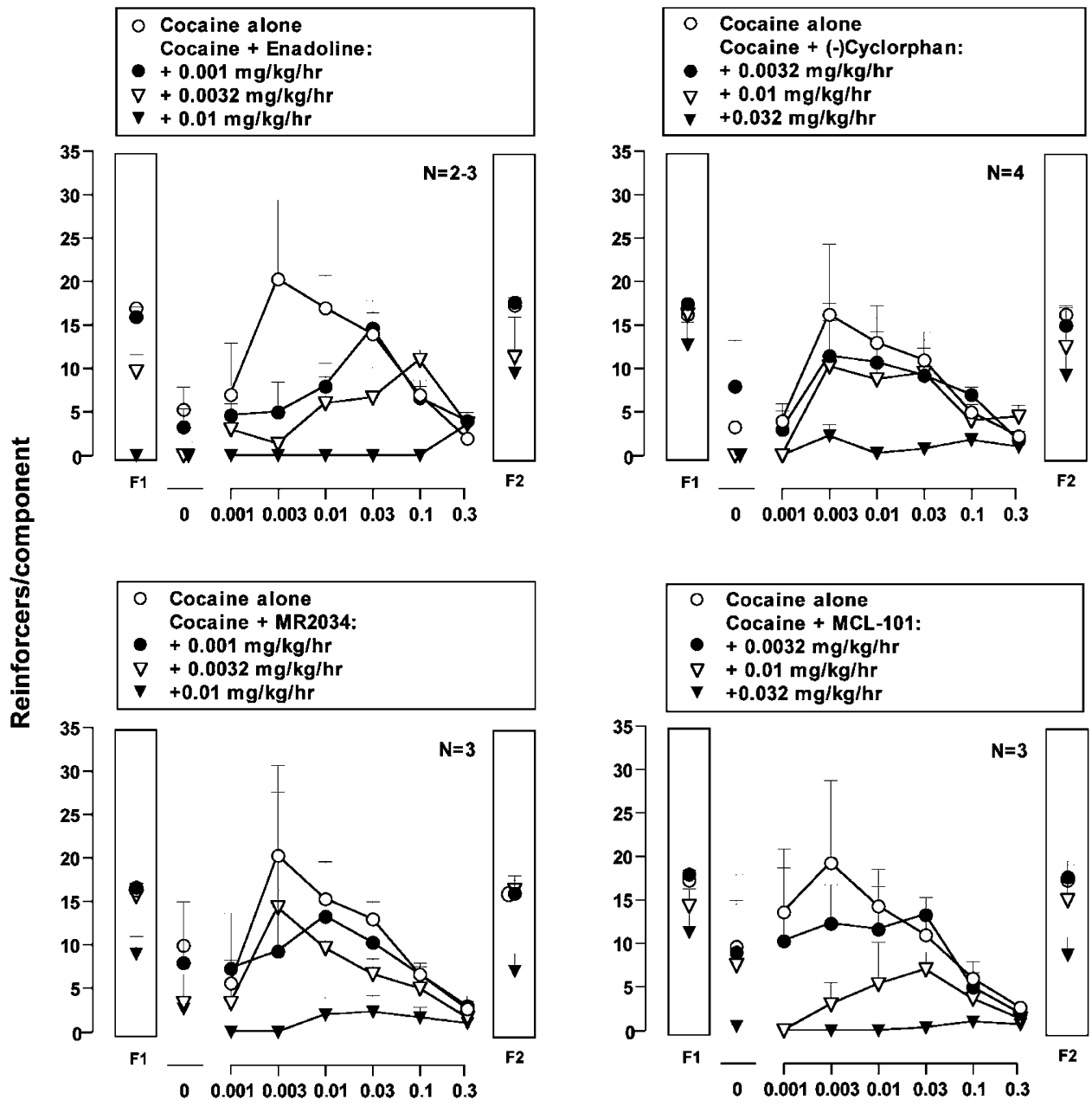

Cocaine (mg/kg/injection, i.v.)

Figure I Acute effects of saline and four $\kappa$-opioid agonists on responding maintained by cocaine and food in rhesus monkeys. The effects of saline and three pretreatment doses of enadoline $(0.001-0.01 \mathrm{mg} / \mathrm{kg} / \mathrm{h}),(-)$ cyclorphan $(0.0032-0.032 \mathrm{mg} / \mathrm{kg} / \mathrm{h}), \mathrm{Mr} 2034(0.001-0.01 \mathrm{mg} / \mathrm{kg} / \mathrm{h})$, and $\mathrm{MCL}-\mathrm{I} 0 \mathrm{I}$ $(0.0032-0.032 \mathrm{mg} / \mathrm{kg} / \mathrm{h})$ on cocaine- and food-maintained responding are shown for groups of monkeys. Three or four monkeys were studied at each drug dose. The one exception was that the highest dose of enadoline $(0.01 \mathrm{mg} / \mathrm{kg} / \mathrm{h})$ was studied in only two monkeys. Abscissae: unit dose of cocaine in $\mathrm{mg} / \mathrm{kg} /$ inj (log scale); ordinates: mean ( \pm SEM) number of saline or cocaine injections delivered during each I5-min drug component or mean ( \pm SEM) number of food pellets delivered during each 5-min food component. Data above ' $\mathrm{O}$ ' represent the mean number of saline injections self-administered. Data above 'FI' and 'F2' represent the mean number of I-g food-pellet deliveries during the first and second food components, respectively. 
self-administration dose-effect curves. The highest levels of cocaine self-administration were maintained by cocaine doses ranging from 0.0032 to $0.032 \mathrm{mg} / \mathrm{kg} / \mathrm{inj}$. In individual monkeys, the peaks of the baseline cocaine self-administration dose-effect curves did not shift by more than a halflog unit over the course of the study.

Acute effects of $\kappa$ agonists. All four $\kappa$ agonists produced dose-dependent and significant decreases in cocaine selfadministration after acute administration. This finding is consistent with previous studies of the effects of chronic $\kappa$ agonist treatment (Mello and Negus, 1998; Negus et al, 1997). Food-maintained responding was also decreased at the highest $\kappa$ agonist doses. The $\kappa$-selective arylacetamide enadoline $(0.01 \mathrm{mg} / \mathrm{kg} / \mathrm{h})$ produced greater decreases in food-maintained responding during the first food component than the mixed $\kappa / \mu$ compounds. Enadoline also produced the most severe side effects (emesis, sedation, salivation), whereas all the mixed $\kappa / \mu$ agonists produced only mild salivation. A morphinan $\kappa$ agonist $/ \mu$ agonist, MCL-101, reduced cocaine self-administration across a broad dose range at doses of 0.01 and $0.032 \mathrm{mg} / \mathrm{kg} / \mathrm{h}$. $(-)$ Cyclorphan, a morphinan $\kappa$ agonist $/ \mu$ antagonist, produced a downward shift in the cocaine dose-effect curve only at the highest dose $(0.032 \mathrm{mg} / \mathrm{kg} / \mathrm{h})$. The benzomorphan, Mr2034, also produced a downward shift in the cocaine dose-effect curve, but this occurred only at the highest dose. Details of effects of these $\kappa$ agonists on cocaine- and food-maintained responding in the group of monkeys (Figure 1) and in individual monkeys (Figure 2) are described below.

Enadoline treatment. Enadoline (0.001-0.01 mg/kg/h) produced dose-dependent and significant decreases in both cocaine self-administration $(p<0.05)$ and food-maintained responding $(p<0.01)$ (Figure 1$)$. Two-way ANOVA showed a significant main effect of $\kappa$ agonist dose on cocaine- and food-maintained responding $(p<0.03$ and 0.01 , respectively) and a significant interaction between $\kappa$ agonist and cocaine dose effects on cocaine self-administration $(p<0.04)$. Enadoline $(0.001$ and $0.0032 \mathrm{mg} / \mathrm{kg} / \mathrm{h})$ decreased self-administration of low cocaine doses $(0.001-0.01 \mathrm{mg} / \mathrm{kg} /$ inj) without altering self-administration of higher cocaine doses $(0.1-0.32 \mathrm{mg} / \mathrm{kg} / \mathrm{inj})$. The highest dose of enadoline studied $(0.01 \mathrm{mg} / \mathrm{kg} / \mathrm{h})$ reduced cocaine self-administration across a wide range of cocaine doses and eliminated
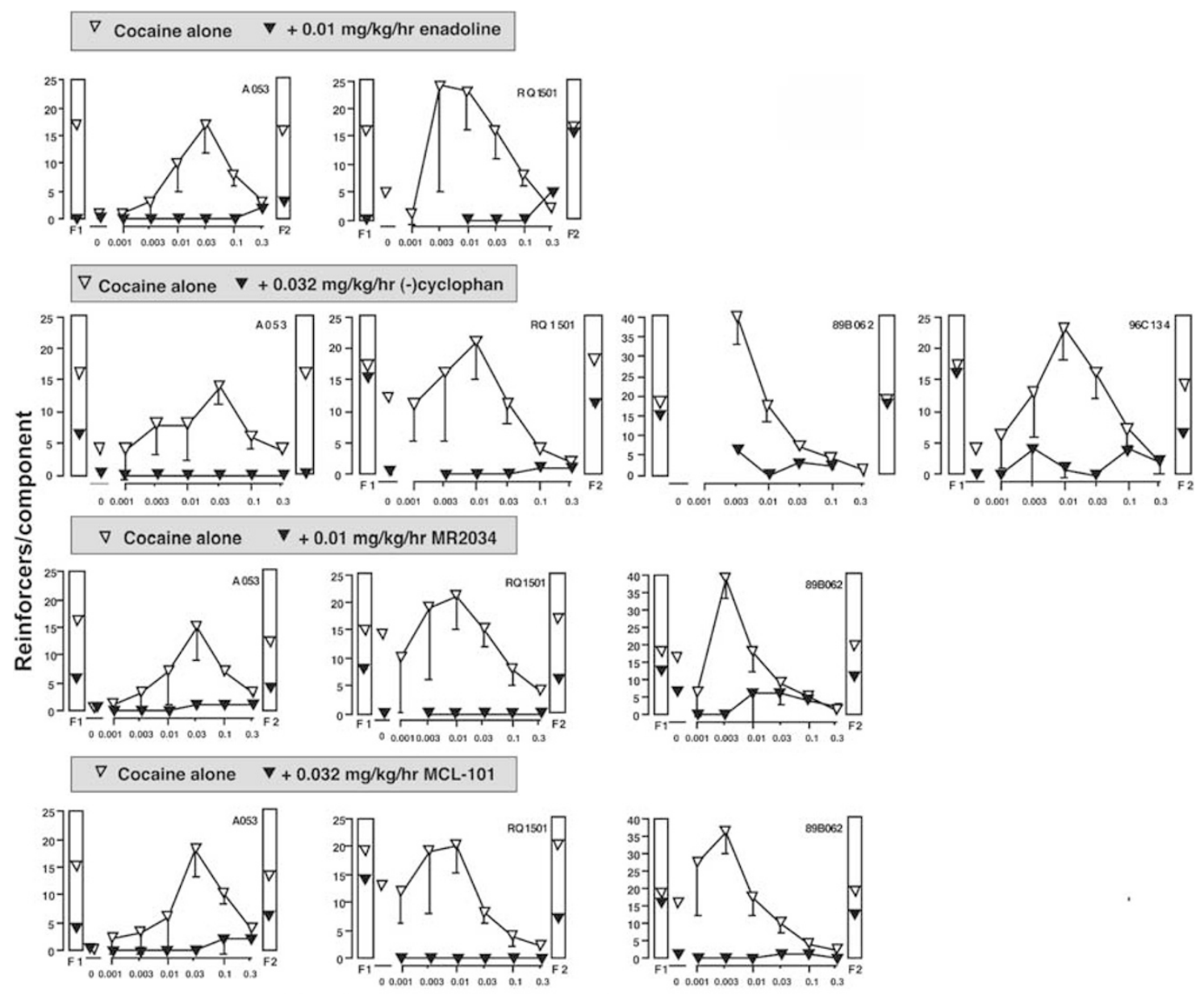

Cocaine (mg/kg/injection, i.v.)

Figure 2 Acute effects of saline and the highest dose of each of four $\kappa$ agonists on responding maintained by cocaine and food in individual rhesus

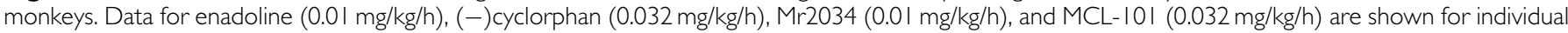
monkeys in rows 1-4, respectively. All other details are the same as in Figure I. 
responding for food during the first food component, but, during the second food component, food-maintained responding increased to $53 \%$ of control levels. The acute effects of enadoline $(0.01 \mathrm{mg} / \mathrm{kg} / \mathrm{h})$ on cocaine- and foodmaintained responding by individual monkeys are shown in the first row of Figure 2. Enadoline nearly eliminated cocaine self-administration and food-maintained responding during the first food component and also produced undesirable side effects, including salivation, emesis, and sedation, in the first two monkeys tested. Owing to the severity of these side effects, this enadoline dose was not evaluated in additional animals.

(-)Cyclorphan treatment. (-)Cyclorphan produced dosedependent and significant decreases in cocaine self-administration $(p<0.05)$ and food-maintained responding $(p<0.05)$ (Figure 1). There was a significant main effect of $\kappa$ agonist dose on both cocaine- and food-maintained responding $(p<0.01)$. $(-)$ Cyclorphan $(0.0032$ and $0.01 \mathrm{mg} /$ $\mathrm{kg} / \mathrm{h}$ ) tended to decrease self-administration of low cocaine doses $(0.001-0.01 \mathrm{mg} / \mathrm{kg} / \mathrm{inj})$ with minimal effects on selfadministration of higher cocaine doses $(0.032-0.32 \mathrm{mg} / \mathrm{kg} /$ inj) or food-maintained responding. The highest dose of $(-)$ cyclorphan $(0.032 \mathrm{mg} / \mathrm{kg} / \mathrm{h})$ nearly eliminated cocaine self-administration across the entire range of doses and reduced responding during the first and second food components to 76 and $56 \%$ of control values, respectively. The acute effects of the highest dose of $(-)$ cyclorphan $(0.032 \mathrm{mg} / \mathrm{kg} / \mathrm{h})$ on food- and cocaine-maintained responding by individual monkeys are shown in the second row of Figure 2. This dose of $(-)$ cyclorphan almost eliminated cocaine self-administration in two monkeys (A053 and RQ1501) and greatly reduced cocaine self-administration in the other two monkeys (89B062 and 96C134). However, the effect of $0.032 \mathrm{mg} / \mathrm{kg} / \mathrm{h}(-)$ cyclorphan on food-maintained responding varied across animals, and only mild side effects (salivation) occurred in some monkeys.

Mr2034 treatment. Mr2034 produced dose-dependent and significant decreases in cocaine self-administration $(p<0.05)$ and food-maintained responding $(p<0.01)$ (Figure 1). There was a significant main effect of $\kappa$ agonist dose on cocaine- and food-maintained responding $(p<0.04$ and $0.01)$. Lower doses of Mr2034 (0.001 and $0.0032 \mathrm{mg} / \mathrm{kg} / \mathrm{h})$ tended to decrease self-administration of low cocaine doses with minimal effects on self-administration of higher cocaine doses or food-maintained responding. The highest dose of Mr2034 ( $0.01 \mathrm{mg} / \mathrm{kg} / \mathrm{h})$ nearly eliminated cocaine self-administration across the entire range of doses and suppressed food-maintained responding during the first and second food components to 56 and $44 \%$ of control values, respectively. The acute effects of the highest dose of Mr2034 (0.01 mg/kg/h) on food- and cocaine-maintained responding by individual monkeys are shown in the third row of Figure 2. Cocaine self-administration was eliminated in one monkey (RQ1501) and greatly reduced in the other two monkeys (A053 and 89B062). Food-maintained responding was reduced during both food components but to a different degree in each monkey. Salivation occurred in some monkeys during treatment with the highest dose of Mr2034, but no vomiting or sedation was observed.
MCL-101 treatment. MCL-101 produced dose-dependent and significant decreases in cocaine self-administration $(p<0.01)$ and food-maintained responding $(p<0.01)$ (Figure 1). There was a significant main effect of $\kappa$ agonist dose on both cocaine- and food-maintained responding $(p<0.01)$. The lowest dose of MCL-101 $(0.0032 \mathrm{mg} / \mathrm{kg} / \mathrm{h})$ tended to decrease self-administration of low cocaine doses without altering self-administration of higher cocaine doses or food-maintained responding. As the MCL-101 dose increased, cocaine self-administration decreased across a broader dose range, and food-maintained responding was less affected. The highest dose of MCL-101 (0.032 mg/kg/h) decreased cocaine self-administration significantly $(p=0.01)$, but it did not significantly change food-maintained responding $(p=0.16)$. MCL-101 nearly eliminated cocaine self-administration across the entire dose range and reduced responding during the first and second food components to 70 and $53 \%$ of control values, respectively. The acute effects of the highest dose of MCL-101 $(0.032 \mathrm{mg} / \mathrm{kg} / \mathrm{h})$ on food- and cocainemaintained responding by individual monkeys are shown in the fourth row of Figure 2. Cocaine self-administration was eliminated in one monkey (RQ1501) and greatly reduced in the other two monkeys (A053 and 89B062). However, the effect of this dose of MCL-101 on food-maintained responding varied across animals. Salivation occurred in some monkeys, but neither vomiting nor sedation was observed.

\section{Study 2: Cocaine Self-Administration-Chronic $\kappa$-opioid Agonist Treatment}

Figure 3 shows the effects of chronic treatment with saline, $(-)$ cyclorphan $(0.0032-0.032 \mathrm{mg} / \mathrm{kg} / \mathrm{h})$, and MCL-101 $(0.0032-0.032 \mathrm{mg} / \mathrm{kg} / \mathrm{h})$ on the average $( \pm$ SEM) number of $0.01 \mathrm{mg} / \mathrm{kg}$ cocaine injections and food pellets earned over 7 consecutive days. During chronic saline treatment, cocaine- and food-maintained responding were stable, and monkeys earned approximately 70 cocaine injections/day and 90 food pellets/day. Both (-)cyclorphan and MCL-101 dose dependently decreased cocaine self-administration $(p<0.05)$. However, the two doses of $(-)$ cyclorphan that significantly decreased cocaine self-administration did not significantly alter food-maintained responding in comparison with the saline treatment baseline. In contrast, the two doses of MCL-101 that significantly decreased cocaine selfadministration also significantly reduced food-maintained responding $(p<0.05)$.

Figure 4 shows the effects of the highest doses of (-)cyclorphan $(0.032 \mathrm{mg} / \mathrm{kg} / \mathrm{h}$; top panel) and MCL-101 $(0.032 \mathrm{mg} / \mathrm{kg} / \mathrm{h}$; bottom panel) on each day of chronic treatment. Both drugs maximally decreased cocaineand food-maintained responding below saline treatment values after 2-3 days of treatment. During the first 3 days of $(-)$ cyclorphan treatment, cocaine- and foodmaintained responding were reduced to 16 and $48 \%$ of control values, respectively. During the first 3 days of MCL101 treatment, cocaine- and food-maintained responding were reduced to 7 and $32 \%$ of control values, respectively. The effects of $(-)$ cyclorphan tended to diminish over time and, on day 7 of treatment, both cocaine- and foodmaintained responding were only 31 and $7 \%$ below saline 

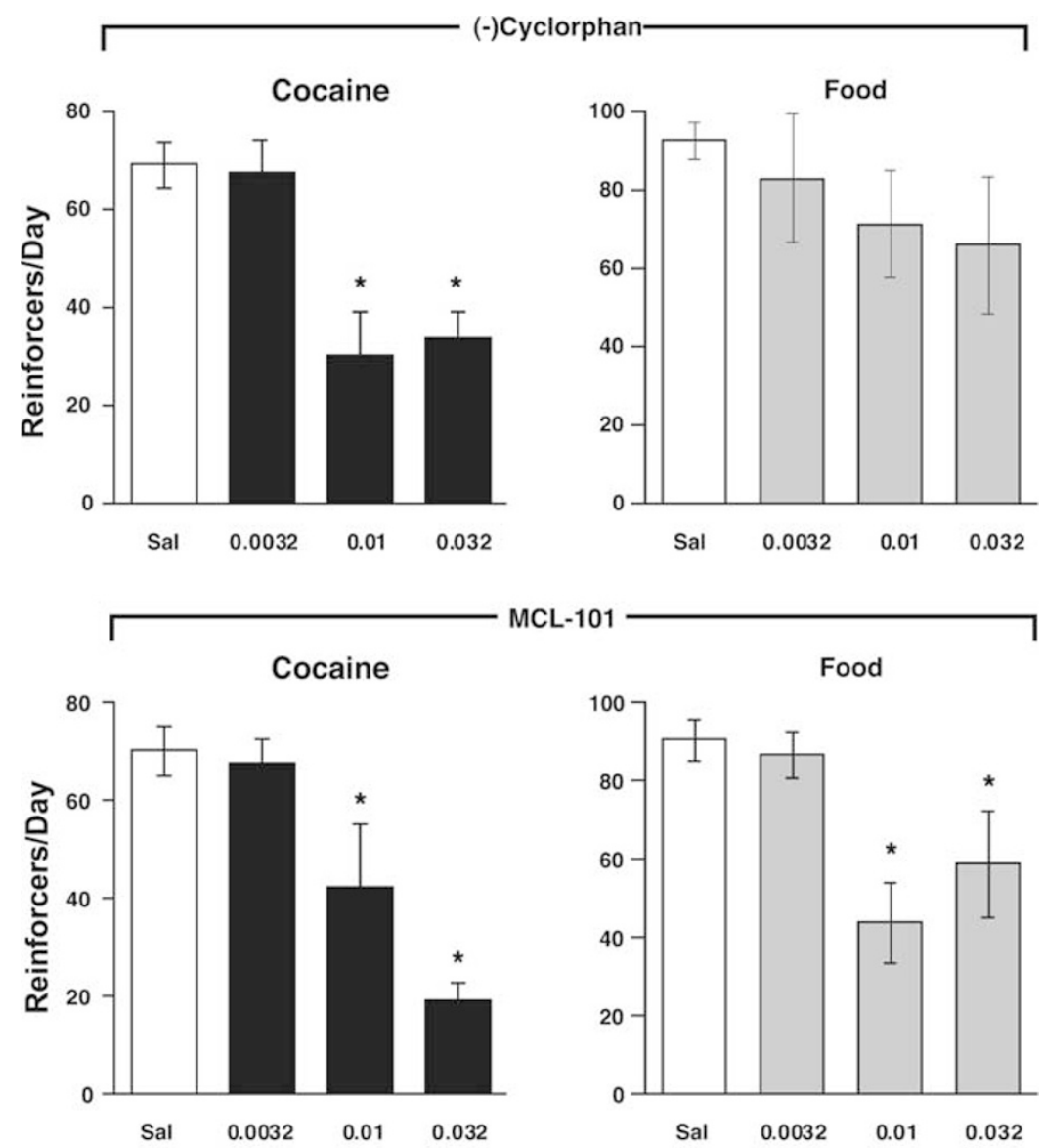

MCL-10
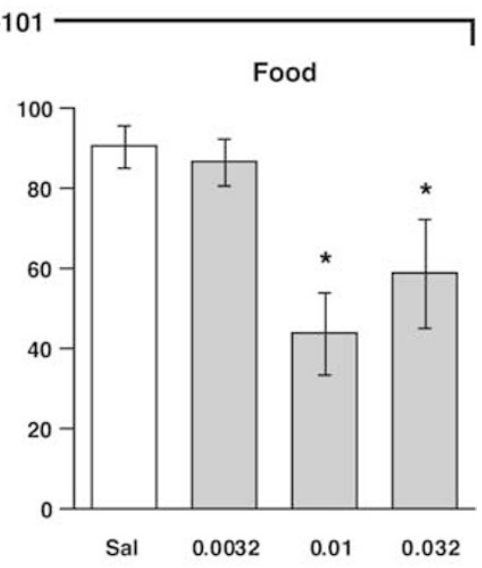

Chronic Treatment $(\mathrm{mg} / \mathrm{kg} / \mathrm{hr})$

Figure 3 Chronic effects of saline, (-)cyclorphan, and MCL-IOI on responding maintained by cocaine and food in rhesus monkeys. The effects of saline and each of three doses of (-)cyclorphan $(0.0032-0.032 \mathrm{mg} / \mathrm{kg} / \mathrm{h})$ (top panels) and MCL-IOI (0.0032-0.032 mg/kg/h) (bottom panels) on responding maintained by $0.01 \mathrm{mg} / \mathrm{kg} / \mathrm{inj}$ cocaine and I-g food pellets were studied for 7 days. Abscissae: dose of $(-)$ cyclorphan or MCL- I0I in mg/kg/h. Data above 'Sal' show the effects of saline control treatments; ordinates: mean number of cocaine injections/day (left panels, maximum $=80$ ) or food pellets/day (right panels, maximum $=100)$. All bars show mean data $( \pm S E M)$ across 7 treatment days for four monkeys. Asterisks $(*)$ indicate points that are significantly different from saline control treatments $(p<0.05)$.

treatment values, respectively (Figure 4, top panel). Similarly, the effects of MCL-101 on food-maintained responding tended to diminish over time, but MCL-101 induced decreases in cocaine self-administration were sustained throughout the treatment period (Figure 4, bottom panel). On day 7 of treatment, cocaine selfadministration was still $68 \%$ below saline treatment levels. As in Study 1, only mild side effects (salivation) were observed during the first $24-48 \mathrm{~h}$ of treatment with $(-)$ cyclorphan and MCL-101.

\section{Study 3: Cocaine Discrimination $-\kappa$ Agonist Substitution and Pretreatment}

$\kappa$ agonist effects on cocaine discrimination were evaluated in both substitution and pretreatment paradigms. Table 1 summarizes the effects of cumulative administration of cocaine and each of the four $\kappa$ agonists. Cocaine (0.013$1.3 \mathrm{mg} / \mathrm{kg}$ ) produced a dose-dependent increase in cocaineappropriate responding, and the training dose of $0.4 \mathrm{mg} / \mathrm{kg}$ cocaine produced $>90 \%$ cocaine-appropriate responding in all monkeys. The highest dose of cocaine $(1.3 \mathrm{mg} / \mathrm{kg})$ also decreased response rates (data not shown). In contrast, cumulative administration of enadoline, $(-)$ cyclorphan, Mr2034, and MCL-101 produced primarily saline-appropriate responding and complete substitution for cocaine was observed in only one of five monkeys following administration of MCL-101. Each $\kappa$ agonist was tested up to doses that eliminated responding in most or all monkeys (data not shown).

Figure 5 shows the effects of $\kappa$ agonist pretreatments on cocaine discrimination dose-effect curves. There were no significant changes in $\mathrm{ED}_{50}$ values for cocaine in the absence and presence of enadoline, (-)cyclorphan, and Mr2034. Only $0.01 \mathrm{mg} / \mathrm{kg}$ MCL-101 significantly affected cocaine $\mathrm{ED}_{50}$ values $(p<0.05)$. Pretreatment with $0.01 \mathrm{mg} / \mathrm{kg} \mathrm{MCL}-$ 101 produced a significant decrease in the cocaine $\mathrm{ED}_{50}$ value compared to cocaine alone, indicating a leftward shift of the cocaine dose-effect curve. Cocaine $\mathrm{ED}_{50}$ values were not significantly altered by enadoline, $(-)$ cyclorphan, or Mr2034. Each $\kappa$ agonist was tested up to doses that eliminated responding in most or all monkeys (data not shown). 

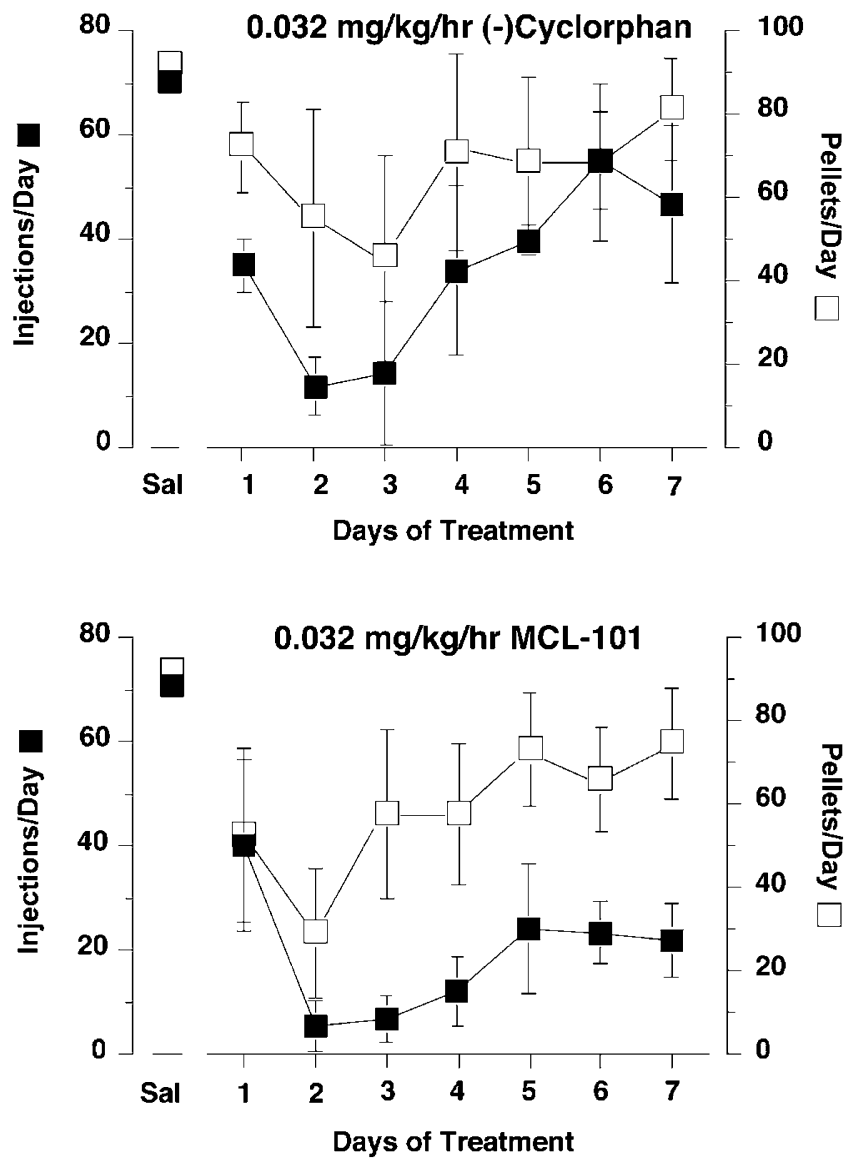

Figure 4 Time course of the chronic effects of $(-)$ cyclorphan and MCL101 in rhesus monkeys. The effects of saline, $0.032 \mathrm{mg} / \mathrm{kg} / \mathrm{h}(-)$ cyclorphan (top panel), and $0.032 \mathrm{mg} / \mathrm{kg} / \mathrm{h} \mathrm{MCL-IOI} \mathrm{(bottom} \mathrm{panel)} \mathrm{on} \mathrm{responding}$ maintained by $0.01 \mathrm{mg} / \mathrm{kg} /$ inj cocaine and I-g food pellets were studied for 7 days. Abscissae: days of $\kappa$ agonist treatment. Points above 'Sal' show mean data from 7 days of saline control treatment; left ordinates: mean number of cocaine injections/day; right ordinates: mean number of food pellets/day. Each point shows mean data $( \pm$ SEM) from four monkeys.

Table I Maximum Percent Cocaine-Appropriate Responding (\% CAR) Observed during Substitution Studies with Cocaine and $\kappa$ Opioid Agonists in Monkeys Discriminating $0.4 \mathrm{mg} / \mathrm{kg}$ Cocaine (i.m.) from Saline (i.m.)

\begin{tabular}{lcccc}
\hline Drug & $\begin{array}{c}\text { Dose range } \\
\text { tested } \\
\text { (mg/kg; i.m.) }\end{array}$ & $\begin{array}{c}\text { Maximum \% } \\
\text { CAR ( } \pm \text { SEM) }\end{array}$ & $\begin{array}{c}\text { \# of monkeys } \\
\text { substituting }\end{array}$ & $\mathbf{N}^{\mathbf{b}}$ \\
\hline Cocaine & $0.013-1.3$ & $100(0)$ & 6 & 6 \\
Enadoline & $0.0001-0.0032$ & $20(20)$ & 0 & 5 \\
(-)Cyclorphan & $0.001-0.1$ & $17(16)$ & 0 & 5 \\
Mr2034 & $0.0001-0.01$ & $14(10)$ & 0 & 5 \\
MCL-101 & $0.001-0.1$ & $25(19)$ & 1 & 5 \\
\hline
\end{tabular}

andicates the total number of monkeys in which the test drug produced $\geqslant 90 \%$ CAR. ${ }^{b}$ Indicates the total number of monkeys tested.

\section{DISCUSSION}

Acute treatments with enadoline, $(-)$ cyclorphan, Mr2034, and MCL-101 produced dose-dependent decreases in cocaine self-administration. At the highest dose studied, each $\kappa$ agonist produced a downward shift in the cocaine self-administration dose-effect curve. However, the behavioral effects of these $\kappa$ agonists differed as a function of the degree of selectivity for the $\kappa$-opioid receptor. Enadoline, a highly selective $\kappa$ agonist, decreased cocaine self-administration only at acute doses that produced profound sedation, emesis, and decreases in food-maintained responding. In contrast, each of the mixed action $\kappa / \mu$ opioids, (-)cyclorphan, Mr2034, and MCL-101, produced only salivation at acute doses that decreased cocaine selfadministration. These findings suggest that mixed action $\kappa / \mu$ opioids may decrease cocaine self-administration with fewer undesirable side effects than highly selective $\kappa$-opioid agonists, such as enadoline. However, the relative degree of $\mu$ agonist or antagonist activity also appears to influence mixed $\kappa / \mu$ effects on cocaine self-administration during chronic treatment. For example, the $\kappa$ agonist $/ \mu$ agonist MCL-101 produced more sustained decreases in cocaine self-administration than the $\kappa$ agonist $/ \mu$ antagonist (-) cyclorphan. Interestingly, the observed $\kappa$ agonist-induced decreases in cocaine self-administration may not require antagonism of the discriminative stimulus effects of cocaine. None of these $\kappa$ agonists attenuated the discriminative stimulus effects of cocaine. Some implications of these findings and their relation to previous studies are discussed below.

\section{$\kappa$-Opioid Agonist Effects on Cocaine Self-Administration}

Acute $\kappa$-opioid agonist effects on cocaine self-administration. The dose-dependent decreases in cocaine selfadministration produced by these four $\kappa$ agonists confirm and extend previous studies in rhesus monkeys (Mello and Negus, 1998; Negus et al, 1997) and rats (Glick et al, 1995; Schenk et al, 1999; for a review see Mello and Negus, 2000). One limitation of our previous studies was that the effects of chronic $\kappa$ agonist administration were evaluated on one or two unit doses of cocaine near the peak of the cocaine doseeffect curve (Mello and Negus, 1998; Negus et al, 1997). However, cocaine self-administration dose-effect curves usually have an inverted ' $U$ ' shape, and a decrease in selfadministration of cocaine doses near the peak of the doseeffect curve may reflect a rightward, leftward, or downward shift in the cocaine dose-effect curve (Mello and Negus, 1996). The present study examined the acute effects of $\kappa$ agonists on complete cocaine dose-effect curves. Under these conditions, $\kappa$ agonists decreased cocaine self-administration across a broad range of doses and produced downward shifts in the cocaine dose-effect curves. Moreover, $\kappa$ agonists were usually more potent in decreasing selfadministration of low cocaine doses than high cocaine doses and similar results were reported in rats (Schenk et al, 1999). These data are consistent with the general finding that drug self-administration behavior maintained by low unit doses is more vulnerable to disruption by pharmacological treatments than drug self-administration behavior maintained by higher unit doses. (For further discussion of this point see Mello and Negus, 1996.)

Chronic $\kappa$-opioid agonist effects on cocaine self-administration. Since acute treatment does not always predict the onset or duration of maximal effects during chronic 

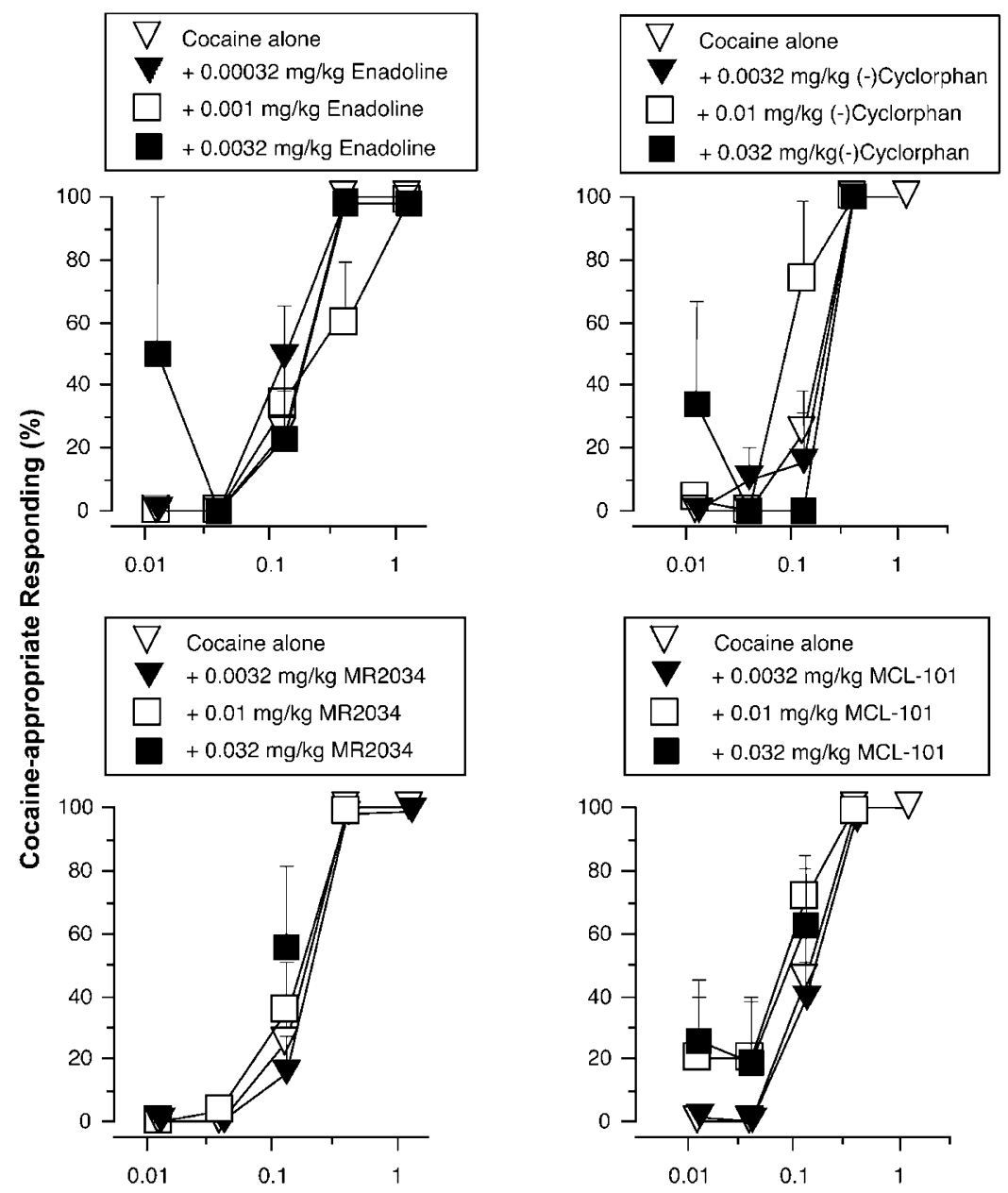

Cocaine $(\mathrm{mg} / \mathrm{kg}, \mathrm{i.m}$.

Figure 5 Mean effects of $\kappa$-opioid agonists on the discriminative stimulus effects of cocaine in six rhesus monkeys. Each panel shows the effects of three pretreatment doses of enadoline (0.00032-0.0032 mg/kg), (-)cyclorphan (0.0032-0.032 mg/kg), Mr2034 (0.0032-0.032 mg/ $/ \mathrm{kg})$, and MCL- I0I (0.0032$0.032 \mathrm{mg} / \mathrm{kg}$ ) on cocaine discrimination dose-effect functions. Abscissae: dose of cocaine in $\mathrm{mg} / \mathrm{kg}$ (log scale); ordinates: mean percent cocaine-appropriate responding. All experiments were conducted in groups of five monkeys. However, some treatments eliminated responding in some monkeys, and data for a given treatment were plotted only if at least two of the five monkeys responded. Accordingly, all points show mean data ( \pm SEM) from two to five monkeys. Owing to highly overlapping dose-effect functions, some data points were adjusted slightly for clarity.

treatment, we also examined the effects of 7 days of treatment with the novel mixed $\kappa / \mu$ opioids $(-)$ cyclorphan and MCL-101. The maximal effects of $(-)$ cyclorphan on cocaine self-administration occurred on the second day of treatment and then gradually diminished. This time course of $(-)$ cyclorphan's effects on cocaine self-administration was similar to that of the $\kappa / \mu$ opioids cyclazocine and bremazocine studied under identical conditions (Mello and Negus, 1998). Like (-)cyclorphan, cyclazocine and bremazocine have primarily $\mu$ antagonist effects in addition to their $\kappa$ agonist effects (Mello and Negus, 1998). However, unlike bremazocine, cyclazocine did not significantly reduce either cocaine- or food-maintained responding. MCL-101 also produced maximal effects on cocaine selfadministration on the second day of treatment, but, in contrast to $(-)$ cyclorphan, its effects were sustained over 7 days. Chronic treatment (7-10 days) with Mr2033 and EKC studied under identical conditions also produced sustained decreases in cocaine self-administration (Mello and Negus,
1998; Negus et al, 1997). Like MCL-101, Mr2033 and EKC have agonist activity at both $\kappa$ and $\mu$ receptors. These findings suggest that nonselective $\kappa$ agonists with $\mu$ agonist activity may produce a more sustained decreases in cocaine self-administration than $\kappa$ agonists with $\mu$ antagonist activity. Interestingly, $\mu$ antagonists alone do not decrease cocaine self-administration by rhesus monkeys (Mello et al, 1993c, 1990), whereas low-efficacy $\mu$ agonists produce selective effects that are sustained for at least 7 days of treatment (Negus and Mello, 2002).

\section{$\kappa$-Opioid Agonist Side Effects during Chronic Administration}

Transient side effects are often observed at the beginning of $\kappa$ agonist treatment (Mello and Negus, 1998, 2000; Negus et $a l$, 1997). In the present study, acute treatment with the high-efficacy $\kappa$ agonist enadoline produced less selective effects on cocaine self-administration and more severe side 
effects than any of the mixed $\kappa / \mu$ opioids. Severe side effects were also observed during chronic treatment with enadoline and with other selective $\kappa$ agonists, such as U50 488 and spiradoline (Mello and Negus, 1998; Negus et al, 1997). In contrast, high doses of mixed action $\kappa / \mu$ opioids produced only mild salivation in some monkeys. These findings are consistent with our previous studies in which chronic treatment with the mixed $\kappa / \mu$ agonists EKC and Mr2033 produced dose-dependent decreases in cocaine self-administration with transient side effects (Mello and Negus, 1998; Negus et al, 1997).

\section{Clinical Implications of $\boldsymbol{\kappa}$-opioid Agonist Side Effects}

The implications of $\kappa$ agonist side effects for their potential usefulness in the clinical treatment of cocaine dependence are unclear (see Mello and Negus, 2000 for discussion). During chronic $\kappa$ agonist treatments, tolerance developed rapidly to the sedative and emetic effects in rhesus monkeys (Mello and Negus, 1998; Negus et al, 1997). Similarly, in the present study, $(-)$ cyclorphan and MCL-101 produced only transient decreases in food-maintained responding. In clinical studies, both selective $\kappa$ agonists and mixed action $\kappa / \mu$ opioids produced dysphoric effects in drug-naive subjects (Pfeiffer et al, 1986). However, it now appears that drug-use history may influence subjective reactions to $\kappa$ opioids. For example, in normal men, enadoline (15 or $25 \mu \mathrm{g}$ ) produced a number of adverse side effects (Reece et $a l, 1994)$, whereas in opioid abusers up to $80 \mu \mathrm{g}$ of enadoline produced dysphoria and sedative effects but no significant sensory disturbances or other side effects (Walsh et al, 2001). Moreover, in opioid abusers, tolerance developed to the dysphoric effects of cyclazocine when gradually increasing doses were administered over 2-4 weeks (Martin et al, 1965, 1966). If tolerance to the adverse side effects of $\kappa$ agonists develops as rapidly in cocaine abusers as it does in rhesus monkeys, transient dysphoria and sedation may not be a serious impediment to treatment.

\section{א-Opioid Agonist Effects on Cocaine Discrimination}

$\kappa$ Agonists did not substitute for cocaine in the present study, and this finding is consistent with previous reports that cocaine and $\kappa$ agonists have distinct discriminative stimulus effects (Broadbent et al, 1995; Negus and Mello, 1999; Spealman and Bergman, 1992; Suzuki et al, 1997). Acute $\kappa$ agonist pretreatment also did not significantly attenuate cocaine discrimination and did not produce significant rightward shifts in the cocaine discrimination dose-effect curve. These data are consistent with previous reports that $\kappa$ agonists often have nonsignificant and highly variable effects on cocaine discrimination (Broadbent et al, 1995; Negus and Mello, 1999; Suzuki et al, 1997; Woolfolk and Holtzman, 1997). The ability of $\kappa$ agonists to block the discriminative stimulus effects of cocaine may be related to the cocaine training dose (Kantak et al, 1999; Spealman and Bergman, 1992, 1994). In squirrel monkeys, for example, $\kappa$ agonists were least effective in blocking cocaine discrimination in monkeys trained with relatively high cocaine training doses $(0.56-1.0 \mathrm{mg} / \mathrm{kg})$ than with lower cocaine training doses $(0.1-0.3 \mathrm{mg} / \mathrm{kg}$ ) (Spealman and Bergman, 1992, 1994). The present study and our previous study
(Negus and Mello, 1999) of $\kappa$ agonist effects on cocaine discrimination in rhesus monkeys used an intermediate training dose of $0.4 \mathrm{mg} / \mathrm{kg}$ cocaine. As a result, it is possible that the failure of $\kappa$ agonists to block consistently cocaine discrimination in our studies was related to the magnitude of the training dose, and $\kappa$ agonists might have antagonized cocaine discrimination if lower training doses had been used. Alternatively, it is possible that the abuse liability of cocaine cannot be accounted for by its discriminative stimulus effects.

It is noteworthy that acute $\kappa$ agonist administration produced different effects on cocaine discrimination and cocaine self-administration in the present study. These findings contrast sharply with the effects of the nonselective dopamine receptor antagonist flupenthixol, which transiently decreased both the discriminative stimulus and the reinforcing effects of cocaine in rhesus monkeys (Negus et $a l, 1996)$. These results suggest that $\kappa$-opioid agonists block the discriminative stimulus effects of cocaine under a narrower range of conditions than dopamine receptor antagonists. One basis for $\kappa$ agonist effects on cocaine self-administration may be that $\kappa$ agonists and cocaine have opposing effects on the mesolimbic dopamine system (Archer et al, 1996; for a review see Mello and Negus, 2000; Shippenberg et al, 2001). However, our findings indicate that $\kappa$ agonists may functionally attenuate some, but not all, of cocaine's abuse-related effects. The mechanisms underlying the complex interactions between $\kappa$-opioid agonists and cocaine remain to be determined.

\section{CONCLUSIONS}

In summary, $\kappa$-opioid agonists consistently decrease cocaine self-administration in rhesus monkeys (Mello and Negus, 1998; Negus et al, 1997) and rats (Archer et al, 1996; Glick et al, 1995; Schenk et al, 1999) with minimal effects on cocaine discrimination (see Negus and Mello, 1999 for further discussion). It now appears that $\kappa$ agonists with some $\mu$ activity produce fewer adverse side effects than highly selective $\kappa$ agonists. However, the optimal $\kappa / \mu$ ratio to selectively reduce cocaine self-administration with minimal side effects remains to be determined. The novel mixed action $\kappa / \mu$ agonist MCL-101 (Neumeyer et al, $2000 a, b, 2001)$ has a more promising profile of activity than the $\kappa$ agonist/ $\mu$ antagonist $(-)$ cyclorphan, and these findings are consistent with previous studies of $\mu$ agonist and antagonist effects on cocaine self-administration (Mello et al, 1990, 1993c; Negus and Mello, 2002). Further studies to evaluate the safety and effectiveness of novel mixed $\kappa / \mu$ agonists for the treatment of cocaine abuse appear to be warranted.

\section{ACKNOWLEDGEMENTS}

The capable technical assistance of Bregiete Luinge and Raoul Fisser in the synthesis of $(-)$ cyclorphan and MCL101 is gratefully acknowledged. We thank Mallinckrodt, Inc., for generously donating levorphanol tartrate. We thank Inge Knudson for excellent assistance with the graphic displays. Preliminary results were presented at the annual meeting of the College on Problems of Drug 
Dependence, 1999, and the International Narcotics Research Conference, 2001. This work was supported by Grants U19DA11007, R01-DA02519, K05-DA00101, T32-DA07252, and K05-DA00360 from the National Institute on Drug Abuse, National Institutes of Health.

\section{REFERENCES}

Archer S, Glick SD, Bidlack J (1996). Cyclazocine revisited. Neurochem Res 21: 1369-1373.

Broadbent J, Gaspard TM, Dworkin SI (1995). Assessment of the discriminative stimulus effects of cocaine in the rat: lack of interaction with opioids. Pharmacol Biochem Behav 51: 379385.

Butelman ER, France CP, Woods JH (1993). Apparent $\mathrm{pA}_{2}$ analysis of the respiratory depressant effects of alfentanil, etonitazene, ethylketocyclazocine (EKC) and Mr2033 in rhesus monkeys. J Pharmacol Exp Ther 264: 145-151.

Caine SB, Negus SS, Mello NK (2000). Effects of dopamine D1-like and D2-like agonists on cocaine self-administration in rhesus monkeys: rapid assessment of cocaine dose-effect functions. Psychopharmacology 148: 41-51.

Crawford CA, McDougall SA, Bolanos CA, Hall S, Berger SP (1995). The effects of the kappa agonist U-50 488 on cocaine-induced conditioned and unconditioned behaviors and Fos immuoreactivity. Psychopharmacology 120: 392-399.

Davis RE, Callahan MJ, Dickerson M, Downs DA (1992). Pharmacologic activity of CI-977, a selective kappa opioid agonist, in rhesus monkeys. J Pharmacol Exp Ther 261: 10441049.

Emmerson PJ, Liu M-R, Woods JH, Medzihradsky F (1994). Binding affinity and selecivity of opioids at mu, delta and kappa receptors in monkey brain membranes. J Pharmacol Exp Ther 271: $1630-1637$.

France CP, Medzihradsky F, Woods JH (1994). Comparison of kappa opioids in rhesus monkeys: behavioral effects and receptor binding affinities. J Pharmacol Exp Ther 268: 47-58.

Glick SD, Maisonneuve IM, Raucci J, Archer S (1995). Kappa opioid inhibition of morphine and cocaine self-administration in rats. Brain Res 681: 147-152.

Gmerek DE, Dykstra LA, Woods JH (1987). Kappa opioids in rhesus monkeys. III. Dependence associated with chronic administration. J Pharmacol Exp Ther 242: 428-436.

Heidbreder CA, Goldberg SR, Shippenberg TS (1993). The kappa-opioid receptor agonist U-69593 attenuates cocaineinduced behavioral sensitization in the rat. Brain Res 616: 335-338.

Hunter JC, Leighton GE, Meecham KG, Boyle SJ, Horwell DC, Rees DC et al (1990). CI-977, a novel and selective agonist for the kappa-opioid receptor. Br J Pharmacol 101: 183-189.

Hutchinson M, Kosterlitz HW, Leslie FM, Waterfield AA, Terenius L (1975). Assessment in the guinea-pig ileum and mouse vas deferens of benzomorphans which have strong antinociceptive activity but do not substitute for morphine in the dependent monkey. Br J Pharmacol 55: 541-546.

Johanson CE, Fischman MW (1989). The pharmacology of cocaine related to its abuse. Pharmacol Rev 41: 3-52.

Kantak KM, Riberdy A, Spealman RD (1999). Cocaine-opioid interactions in groups of rats trained to discriminate different doses of cocaine. Psychopharmacology 147: 257-265.

Kleven MS, Woolverton WL (1990). Effects of continuous infusions of SCH 23390 on cocaine- or food-maintained behavior in rhesus monkeys. Behav Pharmacol 1: 365-373.

Koob GF, Bloom FE (1988). Cellular and molecular mechanisms of drug dependence. Science 242: 715-723.
Kuhar MJ, Ritz MC, Boja JW (1991). The dopamine hypothesis of the reinforcing properties of cocaine. Trends Neurosci 14: 299302.

Line SW, Markowitz H, Morgan KN, Strong S (1989). Evaluation of attempts to enrich the environment of single-caged non-human primates. In: Driscoll JW (ed). Animal Care and Use in Behavioral Research: Regulations, Issues, and Applications. National Agricultural Library: Beltsville, MD. pp 103-117.

Magnan J, Paterson SJ, Tavani A, Kosterlitz HW (1982). The binding spectrum of narcotic analgesic drugs with different agonist and antagonist properties. Naunyn-Schmiedeberg's Arch Pharmacol 319: 197-205.

Maisonneuve IM, Archer S, Glick SD (1994). U50,488 a $K$ opioid receptor agonist, attenuates cocaine-induced increases in extracellular dopamine in the nucleus accumbens of rats. Neurosci Lett 181: 57-60.

Martin WR, Fraser HF, Gorodetzky CW, Rosenberg DE (1965). Studies of the dependence-producing potential of the narcotic antagonists 2-cyclopropylmethyl 2'-hydroxy-5,9-dimethyl-6,7benzomorphan (cyclazocine, Win 20,740, ARC 11-C-3). J Pharmacol Exp Ther 150: 426-436.

Martin WR, Gorodetzky CW, McClane TK (1966). An experimental study in the treatment of narcotic addicts with cyclazocine. Clin Pharmacol Ther 7: 455-464.

Mello NK, Lukas SE, Mendelson JH, Drieze J (1993c). Naltrexonebuprenorphine interactions: effects on cocaine self-administration. Neuropsychopharmacology 9: 211-224.

Mello NK, Mendelson JH, Bree MP, Lukas S (1990). Buprenorphine and naltrexone effects on cocaine self-administration by rhesus monkeys. J Pharmacol Exp Ther 254: 926-939.

Mello NK, Negus SS (1996). Preclinical evaluation of pharmacotherapies for treatment of cocaine and opioid abuse using drug self-administration procedures. Neuropsychopharmacology 14: 375-424.

Mello NK, Negus SS (1998). Effects of kappa opioid agonists on cocaine- and food-maintained responding by rhesus monkeys. J Pharmacol Exp Ther 286: 812-824.

Mello NK, Negus SS (2000). Interactions between kappa opioid agonists and cocaine: preclinical studies. In: Glick SD, Maisonneuve IM (eds). The Archer Conference on Drug Abuse: New Medications. New York Academy of Sciences: New York. pp 104132.

Mendelson JH, Mello NK (1996). Drug therapy: management of cocaine abuse and dependence. $N$ Engl J Med 334: 965-972.

Mori T, Nomura M, Nagase H, Narita M, Suzuki T (2002). Effects of a newly synthesized k-opioid receptor agonist, TRK-820, on the discriminative stimulus and rewarding effects of cocaine in rats. Psychopharmacology 161: 17-22.

Negus SS, Mello NK (1999). Effects of kappa opioid agonists on the discriminative stimulus effects of cocaine in rhesus monkeys. Exp Clin Psychopharm 7: 307-317.

Negus SS, Mello NK (2002). Effects of $\mu$-opioid agonists on cocaine- and food-maintained responding and cocaine discrimination in rhesus monkeys: role of $\mu$-agonist efficacy. J Pharmacol Exp Ther 300: 111-1121.

Negus SS, Mello NK, Lamas X, Mendelson JH (1996). Acute and chronic effects of flupenthixol on the discriminative stimulus and reinforcing effects of cocaine in rhesus monkeys. J Pharmacol Exp Ther 278: 879-890.

Negus SS, Mello NK, Portoghese PS, Lin C-E (1997). Effects of kappa opioids on cocaine self-administration by rhesus monkeys. J Pharmacol Exp Ther 282: 44-55.

Neumeyer JL, Bidlack JM, Zong R, Bakthavachalam V, Gao P, Cohen DJ et al (2000a). Synthesis and opioid receptor affinity of morphinan and benzomorphan derivatives. Mixed kappa agonists and mu agonists/antagonists as potential pharmacotherapeutics for cocaine dependence. J Med Chem 43: 114-122. 
Neumeyer JL, Gu X-H, van Vliet LA, DeNunzio NJ, Rusovici DE, Cohen DJ et al (2001). Mixed $\kappa$ agonists and $\mu$ agonists/ antagonists as potential pharmacotherapeutics for cocaine abuse. Synthesis and opioid receptor binding affinity of $\mathrm{N}$ substituted derivatives of morphinan. Bioorg Med Chem Lett 11: 2735-2740.

Neumeyer JL, Mello NK, Negus SS, Bidlack JM (2000b). Kappa opioid agonists as targets for pharmacotherapies in cocaine abuse. Pharm Acta Helv 74: 337-344.

NIDA (2000). Epidemiologic Trends in Drug Abuse, NIH Publication No. 00-4739A. National Institute on Drug Abuse. pp 99.

Pfeiffer A, Branti V, Herz A, Emrich HM (1986). Psychotomimesis mediated by $\kappa$ opiate receptors. Science 233: 774-776.

Reece PA, Sedman AJ, Rose S, Wright DS, Dawkins R, Rajagopalan R (1994). Diuretic effects, pharmacokinetics, and safety of a new centrally acting kappa-opioid agonist (CI-977) in humans. J Clin Pharmacol 34: 1126-1132.

Ritz MC, Lamb RJ, Goldberg SR, Kuhar MJ (1987). Cocaine receptors in dopamine transporters are related to self-administration of cocaine. Science 237: 1219-1223.

Schenk S, Partridge B, Shippenberg TS (1999). U69593, a kappaopioid agonist, decreases cocaine self-administration and decreases cocaine-produced drug-seeking. Psychopharmacology 144: 339-346.

Schenk S, Partridge B, Shippenberg TS (2000). Reinstatement of extinguished drug-taking behavior in rats: effect of the kappaopioid receptor agaonist, U69593. Psychopharmacology 151: 85-90.

Shippenberg TS, Chefer VI, Zapata A, Heidbreder CA (2001). Modulation of the behavioral and neurochemical effects of psychostimulants by k-opioid receptor systems. In: QuinonesJenab V (ed). The Biological Basis of Cocaine Addiction. Ann. N.Y. Acad. Sci.: New York. pp 50-73.

Shippenberg TS, Rea W (1997). Sensitization to the behavioral effects of cocaine: modulation by dynorphin and k-opioid receptor agonists. Pharmacol Biochem Behav 57: 449-455.
Spealman RD, Bergman J (1992). Modulation of the discriminative stimulus effects of cocaine by $\mathrm{mu}$ and kappa opioids. J Pharmacol Exp Ther 261: 607-615.

Spealman RD, Bergman J (1994). Opioid modulation of the discriminative stimulus effects of cocaine: comparison of $\mu, \kappa$ and $\delta$ agonists in squirrel monkeys discriminating low doses of cocaine. Behav Pharmacol 5: 21-31.

Steiner H, Gerfen CR (1995). Dynorphin opioid inhibition of cocaine-induced, D1 dopamine receptor-mediated immediateearly gene expression in the striatum. J Comparative Neurol 353: 200-212.

Suzuki T, Mori T, Tsuji M, Maeda J, Kishimoto Y, Misawa M et al (1997). Differential effects of mu-, delta- and kappa-opioid receptor agonists on the discriminative stimulus properties of cocaine in rats. Eur J Pharmacol 324: 21-29.

Suzuki T, Shiozaki Y, Masukawa Y, Misawa M, Nagase H (1992). The role of mu- and kappa-opioid receptors in cocaine-induced conditioned place preference. Jpn J Pharmacol 58: 435-442.

Vanderschuren LJM-J, Schoffelmeer ANM, Wardeh G, De Vries TJ (2000). Dissociable effects of the k-opioid receptor agonists bremazocine, U69593, and U50488H on locomotor activity and long-term behavioral sensitization induced by amphetamine and cocaine. Psychopharmacology 150: 35-44.

Walsh SL, Strain EC, Abreu ME, Bigelow GE (2001). Enadoline, a selective kappa opioid agonist: comparison with butorphanol and hydromorphone in humans. Psychopharmacology 157: 151-162.

Wood PL, Charleson SE, Lane E, Hudgin RL (1981). Multiple opioid receptors: differential binding of $\mu, \kappa$ and $\delta$ agonists. Neuropharmacology 20: 1215-1220.

Woolfolk DR, Holtzman SG (1997). and $\kappa$-opioid receptor agonists do not alter the discriminative stimulus effects of cocaine or $d$-amphetamine in rats. Drug Alcohol Depend 48: 209-220. 